\title{
Adjustment to college and academic performance: Insights from Filipino college freshmen in an allied health science course
}

\author{
Mark M. Alipio
}

January 2020

\begin{abstract}
This paper aims to know the relationship between the level of adjustment to college and academic performance of first year Radiologic Technology students of a higher education institution in the Philippines. A descriptive-correlational study using survey questionnaire was employed to 132 respondents who were chosen through stratified random sampling and Slovin's formula. Standard questionnaires were used to gather data on the demographic profile and level of adjustment of the respondents while the academic performance was measured through the Weighted Point Average (WPA) requested from the school's Registrar. Results showed that the majority of the respondents are female (53.8\%), belong to middle income class $(34.8 \%)$, were from STEM (59.1\%) and travel between one kilometer and 10 kilometers to school $(34.1 \%)$. The study reported a moderate level of adjustment and a 2.63 overall WPA of students. Test of difference showed that there is significant difference in the academic adjustment and academic strand taken during SHS $(\mathrm{p}<0.05)$; and in the institutional attachment and proximity of house to school $(\mathrm{p}<0.05)$. Bivariate correlation among variables revealed that there is no significant relationship between the level of adjustment to college and academic performance of first year Radiologic Technology students College ( $p>0.05)$.
\end{abstract}

Keywords: Adjustment, Academic Performance, Freshmen, Higher Education, Allied Health Science, Radiologic Technology, Philippines 


\section{INTRODUCTION}

\section{Background of the Study}

The transition from high school to college marks a distinct step in a student's academic career. The step denotes adjustment from a dependent to independent learner, from studying in a carefully supervised environment with a highly controlled timetable to students learning to manage their own time and make decisions in a more adult and responsible manner. This adjustment poses unnerving problems and few of which are early dropout, difficulty in handling stress and coping with the academic demands, less drive to study and low academic performance (Reddy, Menon, \& Thattil, 2018; Waghachavare, Dhumale, Kadam, \& Gore, 2013).

Gabriela (2010) concluded that there is a higher rate of school dropout due to inability to adapt to school. She found out that $60 \%$ of students who cannot adjust to college drop out early in school. Sahin, Arseven, and Kilic (2016) reported that students who cannot establish good relationships with their friends, teachers and school administration, who do not like the school and the subjects have a higher tendency to be absent from school and to drop out of school. Fan and Wolters (2014) also stated that the individual causes of school dropouts include the difficulty to adjust with the school curriculum.

A study conducted by Clinciu (2013) found out a negative correlation between adjustment to college and stress. The highest correlation was pointed out on the

emotional-affective component. This means that students who have low level of adjustment to college have increased level of stress, particularly in the emotional aspect. This stress was shown to be negatively correlated to academic achievement (Elias, Ping, 
\& Abdullah, 2011). Daniel et al. (2018) argued that stress is perceived by undergraduate students to have a negative impact on their academic performance. Aside from stress, multivariate analysis of Páramo, Vacas, and Rodriguez (2015) revealed that students with lower levels of academic and institutional adjustment to college achieved less well academically than students with intermediate and higher levels of adjustment.

In the Philippines, low academic adjustment of college students of results to poor academic achievement (Alipio, 2020; Calaguas, 2011). It was found out in the study of Hernandez (2017) that first year students from the selected higher-education institutions in Calapan City have poor social adjustment. They can easily adjust to college life in terms of academic and emotional as well as being attached to their institution but it takes them a while to be socially adjusted (Alipio, 2020). The researcher recommends that the guidance counsellors of higher-education institutions may create a guidance program specifically designed for first year college students. This program may include seminar, workshops, psychological testing, and counselling that aim to facilitate their transition and adjustment to college, as well as the enhancement of self-esteem. It also addresses personal, emotional, and psychosocial development of the students.

Given these problems, there is a need to study the level of adjustment and its impact on academic performance of students. Few researches have been published examining the relationship of adjustment to college and academic performance. Rai (2009) revealed that adjustment is significantly related to achievement. Seetha (2009) found out that no significant relationship existed between social adjustment and academic achievement. Chen et al. (2011) investigated that children's social adjustment contributed to academic achievement. On the other hand, Mathur (2010) studied the effects of socio- 
economic status on the achievement and behaviour. The results revealed that achievement was highly correlated with adjustment.

The abovementioned researches mentioned the relationship of students' adjustment to college and academic performance. In the Philippines, higher-education institutions are accepting their first batch of freshmen who just graduated from senior high school, an additional 2 years of education after the country adopted the international standards which is the $\mathrm{K}-12$ basic education curriculum. This new curriculum is implemented by the Department of Education under Republic Act 10533. Thus, this research provides new ideas into how academic strand taken during senior high school as well as the gender, income class, and proximity to house affects the relationship between adjustment of student to college and academic performance. The adjustment of students to college from senior high school is worthwhile to know and the result of this study is beneficial to the Department of Education, high school and college institutions and to the students.

\section{Review of Related Literature}

This section presents the review of literature and related studies of the variables employed in the study. Sources of information were collected from books, journals, magazines and websites.

\section{Adjustment to College}

Having well-adjusted students is one of the purposes of any university since it has been found that students' adjustment can have a remarkable effect on students' academic performance, and having students with better academic performance give more successful image of the university (Kommers P., Junco R., Hills P., 2011). The result of 
"Students Adaptation to College Questionnaire" has disclosed three main contributors of students' adjustment to their educational life and stated that adjusting academically, socially and personal emotionally is very essential for students. Therefore, the relationship between students' academic, social and personal-emotional adjustment with their academic performance can be concentrated by universities to catch better results, having more successful students and being a more prosperous university (Rienties, B., Beausaert, S., Grohnert, T., Niemantsverdriet, S., \& Kommers, P., 2011). The documented difficulties that students experience during the transition to university, combined with the changing needs of students, have brought increased attention to the academic adjustment of first-year university students and interest in improving graduation rates. The poor academic yield, the excessive amount of time invested in degree studies and student attrition are common problems in all European Union countries (Organisation for Economic Co-operation and Development, 2011)

Academic Adjustment. Students adjusts academically well, if they have motivation, believe their capabilities, implement their abilities, be satisfied with their chosen universities and even the level of loyalty to their academic aims (Rienties et al., 2011). According to Rienties et al. (2011) latest studies has figured out that the students' adjustment happen hardly especially between international students and it may become a reason for students' poor learning outcome. This phenomenon mostly occurs when students integration does not make higher education institutes satisfy, and the reason is students are not well-adjusted in order to the universities requirements (Russell et al., 2010). Academic adjustment represents one of the permanent challenges of university pedagogy. The researchers in the field develop studies intended to identify the weight of 
the determining factors so that the students' opportunities to adjust to the university environment and implicitly to academic learning should enhance. Academic adjustment represents an integrating construct, being fairly difficult to define (Clinciu \& Cazan, 2013). The negative effects of academic non-adjustment of students are associated with anxiety, depression, stress, vulnerability, anger, moodiness, mental illness (Clinciu, 2012).

Social Adjustment. Social adjustment of higher education students is defined as the degree of students' adaptation to social manner of their educational life (Rienties et al., 2011). According to Rienties et al. (2011), social adaptation can influence by the reputation of the university in social activities participation of students by the social communities, social relations of students with their friends in the same social networks of students and students' awareness of their own social integration. Several researches determined that there is a huge impact on students' adjustment by colleges and students' social communities especially for freshmen (Rienties et al., 2011). Having unsatisfactory relations with social communities in universities, is one of the reasons students claim to cause them leaving their higher education program (Meeuwisse, M., Severiens, S. E., \& Born, M. P., 2010). In a study conducted in a local public university in Malaysia, (Abdullah, M.C., Elias, H., Mahyuddin, R. \& Uli, J., 2009) found that the best predictor of students' achievement was academic adjustment; however, there was no significant relationship between academic achievement and student social adjustment or students' attachment to university (Abdullah et al., 2009). It has been suggested that transition to university involves movement to a larger, more impersonal structure and increased focus on achievement and its assessment (Azar \& Reshadatjoo, 2014). 
Personal-Emotional Adjustment. Personal-Emotional adjustment of higher education students describes as the degree of students' adaptation to personal and emotional manner of their educational life (Rienties et al., 2011). Students' personal and emotional issues during their educational life stay on an important area of adaptation to college which is named personal-emotional adjustment as the third type of students' adjustment (Rienties et al., 2011). According to Keating, X., Guan, J., Pinero, J., \& Bridges, D., (2010), well physical condition of college students and doing regular physical activities take their virtue and intellectuality in a better personal emotional adjusted situation.

Institutional Attachment. Mohamed (2012) has argued that most of the literature on attachment and university adjustment was focused on parental attachment. Furthermore, a romantic relationship is a better target for intervention than parental attachment (Lapsley \& Edgerton, 2009). The study by Lapsley, Rice, \& FitzGerald (2009) was the first empirical study that examined the influence of peer attachment towards university adjustment. The authors reported that peer attachment was significantly related to academic and personal-emotional adjustment among freshmen. The authors reported that peer attachment was significantly related to academic and personal-emotional adjustment among freshmen.

\section{Academic Performance}

Academic performance of students is defined as the outcome of their studying process and the final result of their academic effort during education Rientes et al., (2011). GPA was enough useful to measure students academic performance in previous studies (Rienties et al., 2011). The current study chooses students GPA as a scale to 
compute their academic performance, as well. According to Rienties et al. (2011), academic achievement of a student is not only determined by his scholarly ability or mental talent, but also it is distinguished by a student's motivation to fulfill his academic aims, believing his 12 capability to accomplish educational demands, trying to attain his academic goals and feeling satisfied of the academic environment.

\section{Adjustment to College and Academic Performance}

A university is a new environment that triggers different reactions among first year students. Thus, life at university for the first year can be exciting and challenging (Habibah E, Noordin N, Mahyuddin RH, 2010). The university terrain is drastically different from that of the school. Students get anxious as they adjust to academic, social, personal and lifestyle challenges that the university presents (Abdullah et al., 2009). It is not surprising that today, it is widely recognized that high school graduation is not sufficient to prepare students for academic and social independence at university. This is a cause of concern as adjustment to the university environment is regarded as an important factor in predicting university outcomes (Petersen I., Louw J., \& Dumont K., 2009). If students do not feel adequate or prepared to cope with the new environment of a college campus, they could easily become susceptible to depression and anxiety.

Higher rates of psychological morbidity are being recorded among first year university students throughout the world (McDermott \& Pettijohn, 2011). Rice (2009) points out that the discourses of academic disciplines in higher education can be confusing and mysterious for the freshman. The confusion can be particularly greater for students coming from cultural and language backgrounds that are different to those underpinning the dominant ideologies of higher education institutions. Monroe (2009) 
revealed that, academic demands increase and new social relations are established when students join higher level institutions. Students are often uncertain of their abilities to meet these demands (Robinson, 2009). Thinking independently might be a new experience for some students who are accustomed to relying on the teacher as the ultimate authority on the course subject (Robinson, 2009). The researchers argue that poor college adjustment correlates with poor academic performance, low graduation rates and poor success later in life. It is therefore intriguing that most high school graduates have academic and social difficulties that delay their adaptation to the new university environment. (Burgess T., Crocombe L., Kelly J., Seet P., 2009) reported that failure to meet the wider challenges faced by students during the transition from secondary to tertiary education impacts on learning outcomes.

\section{Theoretical Framework}

As the support to the study, the researchers used the following theories for the primary theoretical basis of the study undertaken:

Tinto's "Theory of Departure" which states that college outcomes have been examined mainly from the retention and commitment perspectives. However, even retention models stress the importance of experiences. Most current models of student retention include academic and social variables (Tinto, 2002).

In his model derive from the theory of student departure, Tinto placed particular focus on social and academic integration as critical to institutional and goal commitments and, in turn, to college retention. He suggests that students need to separate and successfully merged into academic and social aspects of college life in order to persist in college. 
Tinto's theory is most relevant to students who reside on campus who may have the greatest opportunities to successfully integrate into college life. Conversely, he suggests that commuter students may struggle the most with the integration process as they spend less time on campus compared to residential students.

The Alexander Astin's "Theory of Involvement" was also used, in which emphasis is placed on the input (past experiences and personal characteristics) and the college environment as related to the college outcomes, such as academic performance, adjustment, or retention (Astin A., 1982).

\section{Conceptual Framework}

Figure 1 shows the conceptual paradigm presenting the relationship of the variables of the study. The independent variable is the adjustment to college which can be subdivided into four parts namely the academic adjustment, social adjustment, personalemotional adjustment and institutional attachment. The dependent variable is the academic performance of first year radiologic technology students. Also shown in the figure is the moderating variable which is the demographic profile of the students. The demographic profile includes gender, financial status, and academic strand taken during senior high school (SHS) and proximity of the house to school. 
Independent Variable

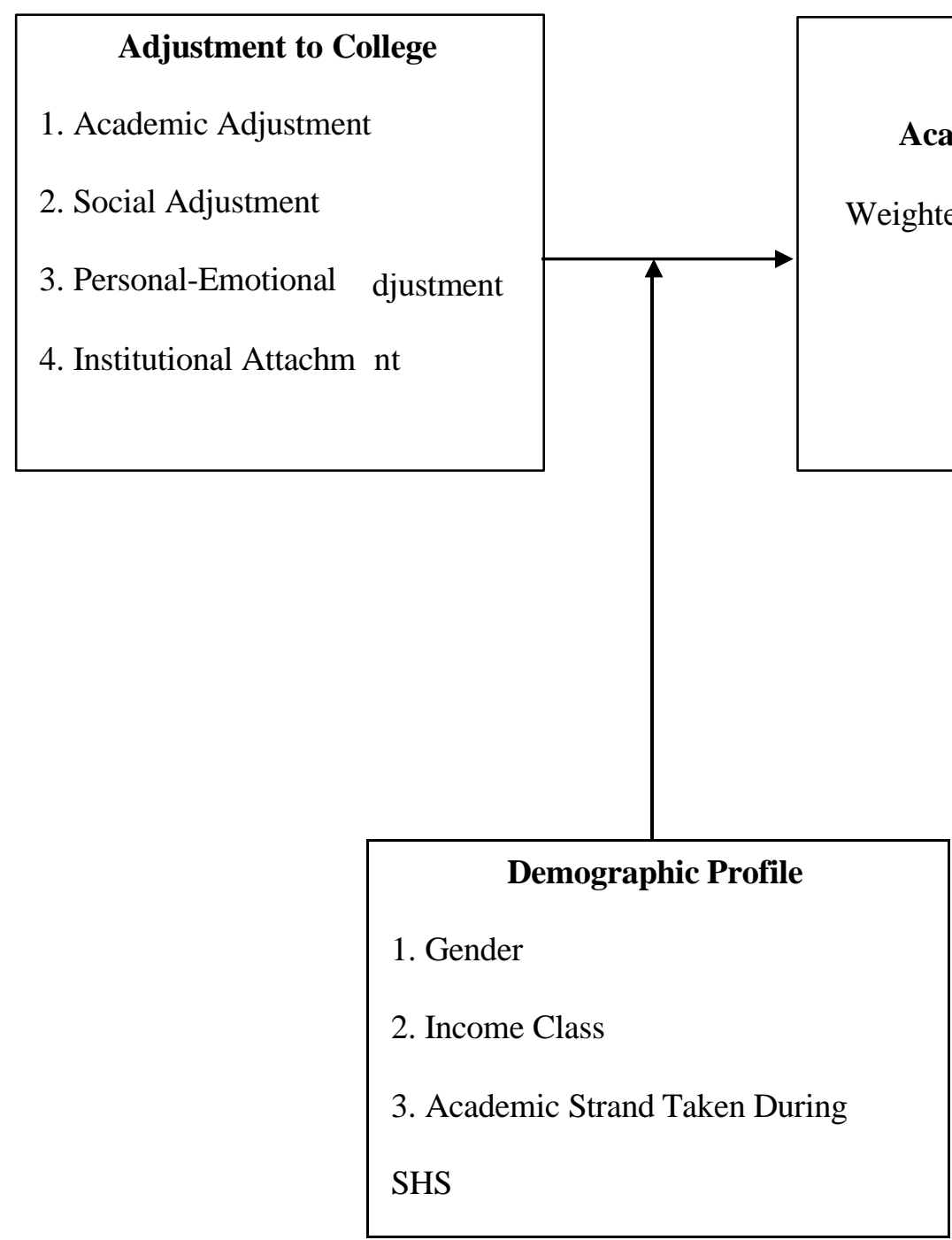

\section{Moderating Variable}

Figure 1. The Conceptual Paradigm Showing the Relationship Among the Variables of the Study

\section{Dependent Variable}

Academic Performance

eighted Point Average (WPA) 


\section{Statement of the Problem}

The thrust of the study is to determine the relationship between adjustment to

college and academic performance of $1^{\text {st }}$ year Radiologic Technology students of a higher education institution in the Philippines. Specifically, it sought to answer the following questions:

1. What is the demographic profile of $1^{\text {st }}$ year Radiologic Technology students in terms of:

\subsection{Gender}

1.2 Income class

1.3 Academic strand taken during SHS

1.4 Proximity of house to school

2. What is the level of adjustment to college of $1^{\text {st }}$ year Radiologic Technology students?

3. What is the academic performance of $1^{\text {st }}$ year Radiologic Technology students in terms of Weighted Point Average (WPA)?

4. Is there significant difference in the adjustment to college when students are grouped according to:

\subsection{Gender}

4.2 Income class

\subsection{Academic strand taken during SHS}

\subsection{Proximity of house to school}

5. Is there a significant relationship between the level of adjustment to college and academic performance of $1^{\text {st }}$ year Radiologic Technology students? 


\section{Hypotheses}

The researcher employed the following null hypotheses tested at 0.05 level of significance. This states that:

H1: There is no significant difference in the adjustment to college when students are grouped according to gender, income class, academic strand taken during SHS and proximity of house to school.

$\mathrm{H} 2$ : There is no significant relationship between the level of adjustment to college and academic performance of $1^{\text {st }}$ year radiologic technology students.

\section{Definition of Terms}

The following are the definition of the terms being used in the study. The following terms were defined conceptually:

Adjustment. It is the process by which a living organism maintains a balance between the needs and the circumstances. It also refers to a student's interaction with his or her environment. His definition referenced student's academic achievement and personal growth as measures of the adjustment Abdullah et al., (2009).

In the present study scores obtained by the students in four areas of adjustment i.e. academic, social, personal-emotional and institutional attachment.

Emotional Adjustment. This refers to an individual's adaptation in emotional relationships within and with other people, both inside and outside the school, as reflected in the individual's attitudes and behavior (Najimi A, Moazemi Goudarzi A, Sharifirad G., 2012). 
Social Adjustment. This refers to an individual's adaptation in social relationships with other people, both inside and outside the school, as reflected in the individual's attitudes and behaviour (Wilson, 2013).

In this study it is the mean of the total degree achieved by the respondent on the items related to social adjustment in the university life adjustment scale.

Academic Achievement. This refers to the performance in school in a standardized series of educational tests. The term is more generally used to describe performance in the subjects of the curriculum. It refers to the marks scored in the Quarterly test that is designed and administered to the sample of students by the investigator himself (Peter James K., Inter Andy J., Tracy O., 2014).

In the present study Weighted Point Average obtained by the students in preliminary term was taken as their academic achievement.

Personal (emotional) adjustment. This refers to the student ability to achieve self-satisfaction within different activities.

In this study it is the mean of the total degree achieved by the respondent on the items related to emotional adjustment in the university life adjustment scale.

\section{Significance of the Study}

The result of the study will provide relevant information to the people concerned especially:

High School Students. This research would help the students choose the right academic strand as preparation to planned college degree. 
First Year Students. This research would help the students know how they would be able to adjust to college since it is the first time or first year for the senior high school graduates to move to college.

School Administrator and Faculty. The findings of the study would serve as the basis of the administrator in formulating the most excellent way to discipline and to teach students to improve their performance and be able to distinguish the adjustments for the $1^{\text {st }}$ year students of higher education institution in the Philippines.

Future Researchers. This study serves as a major course requirement to establish facts from acknowledged norms and so it could be benefit for future use. The results of the study can be utilized for future studies. 


\section{METHODOLOGY}

\section{Design}

A survey design was used for this descriptive quantitative research study investigating the level of adjustment to college and academic performance of first year radiologic technology students of a higher education institution in the Philippines. Specifically, this study utilized a nonexperimental survey research design, using questionnaires with the intent of generalizing from a sample to a population. According to Creswell (2013), several advantages for using survey methods include (a) surveys are relatively economical; (b) the turnaround in data collection is fast; (c) they are useful in describing the characteristics of a large population; and (d) as a result, large samples are practical, making the results statistically important even when examining multiple variables.

In addition to surveys, a correlational research design was used. In general, a correlational study is a quantitative method of research in which two or more quantitative variables from the same group of respondents are used to determine if there is a relationship between the variables and the degree of that relationship (Mitchell \& Jolley, 2012).

\section{Respondents}

The respondents were the Radiologic Technology freshmen of higher education institution in the Philippines who graduated from senior high school from the last academic year regardless of the type of school graduated, who entered the First Semester of Academic Year 2018- 2019 and who were enrolled as regular students. The researchers used stratified random sampling in the conduct of the study employing sections for Introduction to Radiologic Technology and Health Care (RT-100) as the strata. 
Thompson (2012) states that stratified random sampling is a probability sampling technique that involves the division of a population into smaller groups known as strata. In stratified random sampling or stratification, the strata are formed based on members' shared attributes or characteristics. Data of the students were obtained from the school's office of the Registrar and the percentage weights are given according to sections for Introduction to Radiologic Technology and Health Care (RT-100): Section BSRT1-51A (23.6\%), BSRT1-51B (25.6\%), BSRT1-51C (25.6\%) and BSRT1-51D $(25.1 \%)$.

For facility and ease, the 131 computed sample size was adjusted to 132 . To spread the computed sample size of 132 , the percentage weights were multiplied against the sample size to get the samples of each stratum. Shown in Table 1 is the summary of computation for the sample size per stratum.

Table 1. Summary of Computation for the Sample Size Per Stratum

\begin{tabular}{|l|c|c|}
\hline Stratum & Percentage Weights & Sample size per stratum \\
\hline BSRT1-51A & $23.6 \%$ & 31 \\
\hline BSRT1-51B & $25.6 \%$ & 34 \\
\hline BSRT1-51C & $25.6 \%$ & 34 \\
\hline BSRT1-51D & $25.1 \%$ & 33 \\
\hline
\end{tabular}

\section{Data Gathering Instrument}

Primary data were taken from the responses to the demographic profile questionnaire which was developed by the researchers to collect data on gender, income class, academic strand taken during senior high school and proximity of house to school and the standard Student Adaptation to College Questionnaire (SACQ) which was developed by Baker and Siryk (1989) and used in the study of Petersen et al., (2009) and Clinciu and Cazan (2014). The SACQ is utilized to measure the quality of students' adjustment to college. It is a 67-item self-report questionnaire used as a diagnostic tool for identifying students experiencing difficulty adjusting to college and who may benefit from remedial interventions, and as an assessment tool in research. Four different 
dimensions of adjustment are identified in the scale namely the academic, social, personal-emotional adjustment, and institutional attachment. The scale thus consists of four sub-scales, with each sub-scale measuring a different aspect of adjustment. The answer format used was a Likert scale ranging from 1 (strongly disagree) to 5 (strongly agree). The scale was scored such that a high score corresponds with a high level of adjustment. Because item numbers 1, 3, 4, 5, 8, 9, 13, 14, 15, 16, 18, 19, 23, 24, 26, 27 , $30,33,36,37,43,44,46,47,50,53,54,55,62,63,65,66$ and 67 are positively-phrased questions, these were scored in a way that 5 corresponds to strongly agree and 1 corresponds to strongly disagree. Because item numbers $2,6,7,10,11,12,17,20,21$, $22,25,28,29,31,32,34,35,38,39,40,41,42,45,48,49,51,52,56,57,58,59,60,61$ and 64 are negatively-phrased questions, scoring was reversed in a way that 5 corresponds to strongly disagree and 1 corresponds to strongly agree.

Petersen et al. (2009) reported the alpha reliabilities of the SACQ sub-scales. Academic adjustment (24 items) has a Cronbach's alpha of .84, social adjustment (20 items) has a Cronbach's alpha of .84 , personal-emotional adjustment (15 items) has a Cronbach's alpha of .78 and attachment (15 items) has a Cronbach's alpha of .86. Nunnally (1978) asserted that questionnaires used in survey research should have at least .70 Cronbach's alpha to become reliable. The overall mean of each subscale was calculated and interpreted based on this scale:

\section{Range of Means Category Meaning}

4.20-5.00 Very High Students adjust to college all of the time.

3.40-4.19 High Students adjust to college very often.

2.60-3.39 Moderate Students adjust to college often. 
1.80-2.59 Low Students adjust to college sometimes.

1.00-1.79 Very Low Students do not adjust to college.

Secondary data which include the student's Weighted Point Average (WPA) for the prelim term of the first semester, Academic Year 2018-2019 were collected from the school's office of the Registrar.

\section{Ethical Considerations}

The researchers obtained the approval of the Research Ethics Committee of the said institution before conducting the study. Upon approval of the request to conduct the study, the researcher gave a complete overview of the research study to the prospective research respondents. Written informed consent was then obtained from the respondents. Included in the written informed consent are the direct benefits of the respondents from the study, associated risks and provision of a counselor to provide appropriate intervention to research respondents during and after the research. Respondents were informed that the responses from the questionnaire were utilized for the results of the study. Students who are incapable of giving personal consent and/or to express their decision sought their consent through their parents or guardians. Moreover, the respondents were given the freedom to answer the questions in the survey questionnaires. All the answered questionnaires were kept into confidentiality and the results is for research purposes only. Other external entities that are not connected with the study who will ask for any information about the data gathered were declined by the researchers. Respondents' participation was voluntary and the researchers explained to the respondents that they are free to withdraw at any time during the study. After 
collecting and processing the data, hard copies of information were burned and soft copies were deleted.

\section{Research Procedure}

This study started with the conceptualization of the problem and identification of variables as these are drawn in a conceptual paradigm. Then, specific questions were asked on the basis of the problems identified. In gathering of data, a survey questionnaire was formulated consisting of specific item statements that elicit information and data. There were two parts of questionnaire employed in the study. First, was the demographic profile which was used to gather data on gender, income class, academic strand taken during senior high school and proximity of house to school. Second, was the adjustment to college questionnaire which was used to measure the level of adjustment of radiologic technology freshmen to college. The survey questionnaire that forms part of this proposal was submitted to validators for comments, suggestions, and improvement both in content and format. After the validators have gone over and passed upon the questionnaire, this was finalized incorporating the corrections made. After the survey questionnaire was finalized, a letter of permission to conduct the study was given to the Program Chair of Radiologic Technology Program of the said institution. It was given by the researchers personally to obtain an immediate approval. Questionnaires were then administered on the respondents. After the questionnaires were retrieved, the responses were tabulated, analyzed and interpreted using the appropriate statistical tools. Another letter was sent to the office of Registrar of the said institution to request for a copy of respondents' grades during prelim term of the First Semester, Academic Year 2018- 
2019. After the two data were collected, these were analyzed using Pearson product moment correlation, t-test and ANOVA.

Statement of the problem number 5 which determines the correlation between level of adjustment and academic performance was calculated in different manner. The scoring guide of the school for academic performance in terms of Weighted Point Average (WPA) is reported in a way that 1.0 corresponds to the highest WPA while 5.0 corresponds to the lowest WPA. This is an exact reverse for the scoring guide used to measure the level of adjustment of students which states that 5 corresponds to the highest level of adjustment and 1 corresponds to the lowest level of adjustment. To avoid negative correlation and other statistical biases, the WPA of students was reversed and converted in a way that a score of 5.0 means that the student has a WPA of 1.0 and a score of 1.0 means that the student has a WPA of 5.0.

\section{Data Analysis}

In analyzing and interpreting the data gathered for this study, the following statistical tools were employed:

1. Frequency distribution, percentage, ranking and arithmetic mean to describe the independent, dependent and moderating variables.

2. Pearson product moment correlation (Pearson R) to determine the significant relationships between the variables.

3. T-test to determine the significant difference in the level of adjustment to college and academic performance when the respondents are grouped according to gender. 
4. Analysis of Variance (ANOVA) to determine the significant difference in the level of adjustment to college and academic performance when the respondents are grouped according to income class, academic strand taken during senior high school and proximity of house to school.

\section{Scope and Limitations of the Study}

The study covered only the respondents from one undergraduate program of a higher education institution in the Philippines, which is the Radiologic Technology program. It sought to know the adjustment to college of students and its impact on academic performance. The study utilized the Weighted Point Average (WPA) of students in prelim term only due to time constraint. The duration of the study covered the months of June 2018 to October 2018. 


\section{RESULTS AND DISCUSSIONS}

This section presents the analysis and interpretation of the gathered data which are presented in descriptive and tabular form. The results and discussions answer the statement of the problem presented in the previous section.

1.What is the demographic profile of $1^{\text {st }}$ year Radiologic Technology students in terms of:

1.1 Gender

1.2 Income Class

1.3 Academic strand taken during SHS

1.4 Proximity of house to school

Table 2. Demographic Profile of $1^{\text {st }}$ Year Radiologic Technology Students

\begin{tabular}{ccc}
\hline Gender & Number of Respondents & Percentage(\%) \\
\hline Male & 61 & 46.2 \\
Female & 71 & 53.8 \\
\hline Total & 132 & 100 \\
\hline
\end{tabular}

Table 2 represents the demographic profile of respondents in terms of gender. Data showed that there are 61 male respondents with corresponding percentage of $46.2 \%$ and 71 female respondents with corresponding percentage of $53.8 \%$. Total number of respondents are 132 with majority of the respondents are female first year Radiologic Technology students. 
Table 3. Income Class of $1^{\text {st }}$ Year Radiologic Technology Students

\begin{tabular}{ccc}
\hline Income Class & Number of Respondents & Percentage (\%) \\
\hline Middle class & 46 & 34.8 \\
Low middle income & 34 & 25.8 \\
Poor & 16 & 12.1 \\
Low income (but not poor) & 14 & 10.6 \\
Upper middle income & 14 & 10.6 \\
Upper income (but not rich) & 5 & 3.8 \\
Rich & 3 & 2.3 \\
\hline Total & 132 & 100 \\
\hline
\end{tabular}

Table 3 represents the demographic profile of respondents in terms of financial status. Data showed that 46 of the respondents belong to the middle class with percentage of $34.8 \%$. Thirty-four of the respondents belong to the low middle income level of income class with percentage of $25.8 \%$. Sixteen of the respondents belong to the poor income class with the corresponding percentage of $12.1 \%$. Fourteen respondents belong to the low income (but not poor) with the corresponding percentage of 10.6\%. Fourteen respondents belong to the upper middle income with corresponding percentage of $10.6 \%$. Upper income (but not rich) has five number of respondents with the corresponding percentage of $3.8 \%$. Lastly, three respondents belong to the rich level of income class with the corresponding percentage of $2.3 \%$.

This means that majority of the respondents belong to the middle class level of income class while the least number of respondents belongs to the rich level of income class. 
Table 4. Academic Strand Taken During SHS by $1^{\text {st }}$ Year Radiologic Technology Students

\begin{tabular}{ccc}
\hline $\begin{array}{c}\text { Academic Strand Taken } \\
\text { During SHS }\end{array}$ & Number of Respondents & Percentage(\%) \\
\hline STEM & 78 & 59.1 \\
GAS & 28 & 21.2 \\
HUMSS & 12 & 21.2 \\
ABM & 5 & 3.8 \\
Others & 9 & 6.8 \\
\hline Total & 132 & 100 \\
\hline
\end{tabular}

Presented in Table 4 is the demographic profile of respondents in terms of academic strand taken during their Senior High School. Data showed that there were 78 respondents took STEM during their SHS with the corresponding percentage of $59.1 \%$. There were 28 respondents who took GAS during their SHS with the corresponding percentage of $21.2 \%$ while 12 respondents took HUMSS during their SHS with the corresponding percentage of $21.1 \%$. Also, five respondents took ABM during their SHS with the corresponding percentage of $3.8 \%$. Lastly, nine respondents chose others with the corresponding percentage of $6.8 \%$.

This means that majority of the respondents took STEM during their SHS while the least number of respondents took ABM during their SHS.

Table 5. Proximity of House to School

\begin{tabular}{ccc}
\hline Proximity of House to School & Number of Respondents & Percentage (\%) \\
\hline Between 1 kilometer and 10 & 45 & 34.1 \\
kilometer & 44 & 33.3 \\
More than 10 kilometer & 43 & 32.6 \\
Less than 1 kilometer & 132 & 100 \\
\hline Total & &
\end{tabular}


Table 5 represents the demographic profile of respondents in terms of proximity of house to school. Data showed that there were 45 respondents who live within the bracket between one kilometer and 10 kilometer with the corresponding percentage of $34.1 \%$. There were 44 respondents who belong to the bracket of more than 10 kilometer with the corresponding percentage of $33.3 \%$. Lastly, there were 43 respondents who belong to more than less than 1 kilometer with the corresponding percentage of $32.6 \%$.

This means that majority of the respondents lived between one kilometer and 10 kilometer while the least number of respondents lived less than one kilometer from the school.

2.What is the level of adjustment to college of 1st year radiologic technology students?

Table 6. Level of Adjustment to College

\begin{tabular}{lcc}
\hline \multicolumn{1}{c}{ ADJUSTMENTTO } & Mean & DescriptiveEquivalent \\
\hline Institutional Attachment & 3.09 & Moderate \\
Academic Adjustment & 3.07 & Moderate \\
Social Adjustment & 3.06 & Moderate \\
Personal-Emotional Adjustment & 3.01 & Moderate \\
\hline \multicolumn{3}{c}{ Overall Mean } \\
Legend: 4.20-5.00=Very High; 3.40-4.19=High; 2.60-3.39= \\
Moderate; 1.80-2.59=Low; 1.00-1.79=Very low
\end{tabular}

Presented in Table 6 is the level of Adjustment to College among first year Radiologic Technology students/. The institutional adjustment has a mean score of 3.09 which corresponds to moderate. This means that students adjust to college often in terms of institutional attachment. The academic adjustment has a mean 
score of 3.07 which corresponds to moderate. This means that students academically adjust to college often. The social adjustment has a mean score of 3.06 which corresponds to moderate. This means that students socially adjust to college often. The personal-emotional attachment has a mean score of 3.01 which corresponds to moderate. This means that students adjust to college often in terms of personal-emotional aspect. The overall mean score for adjustment to college is 3.06 which correspond to moderate. This means that students adjust to college often.

The findings of this problem conform to the study of Kumar (2010) states that the parents have to be guided on how they have to care and educate their children in the changing scenario. The parents should be oriented about, the needs of the changing social set up, problems of the children, and various procedures for the proper development of the children.

3. What is the academic performance of 1st year Radiologic Technology students in terms of Weighted Point Average (WPA)?

Table 7. Weighted Point Average

\begin{tabular}{cc}
\hline Term & WPA \\
\hline Prelim & 2.63 \\
\hline
\end{tabular}

Presented in Table 7 is the academic performance of first year Radiologic Technology students in terms of Weighted Point Average (WPA). This means that during the term prelim, the overall Weighted Point Average of students is 2.63. In school system, the average is above the passing rate. 
4.Is there significant difference in the adjustment to college when students are grouped according to:

\subsection{Gender}

\subsection{Financial status}

\subsection{Academic strand taken during SHS}

4.4 Proximity of house to school

Table 8. Independent t-test in the level of adjustment to college when grouped according to gender

\begin{tabular}{lccccc}
\hline ADJUSTMENT TOCOLLEGE & $\mathrm{t}$ & $\mathrm{df}$ & Sig.(2-tailed) & Decision & Interpretation \\
\hline Academic Adjustment & .495 & 130 & .622 & Accept & Not Significant \\
Social Adjustment & .138 & 130 & .890 & Accept & Not Significant \\
Personal-Emotional Adjustment & -.114 & 130 & .910 & Accept & Not Significant \\
Institutional Attachment & -.569 & 130 & .570 & Accept & Not Significant \\
\hline
\end{tabular}

Alpha: 0.05

Table 8 represents the independent t-test in the level of adjustment to college when grouped by gender. In terms of academic adjustment, the tabular value is .495 and the degree of freedom is 130 . Because the p-value of .622 is greater than 0.05 alpha level of significance, the null hypothesis is accepted. Therefore, there is no significant difference in the level of academic adjustment when respondents are grouped according to gender. This means that the level of academic adjustment to college is not affected by gender. In terms of social adjustment, the tabular value is .138 and the degree of freedom is 130 . Because the p-value of .890 is greater than 0.05 alpha level of significance, the null hypothesis is accepted. Therefore, there is no significant difference in the level of social adjustment when respondents are grouped according to gender. In terms of 
personal-emotional adjustment, the tabular value is -.114 and the degree of freedom is 130. Because the p-value of .910 is greater than 0.05 alpha level of significance, the null hypothesis is accepted. Therefore, there is no significant difference in the level of personal-emotional adjustment when respondents are grouped according to gender. Lastly, in terms of institutional attachment, the tabular value is -.569 and the degree of freedom is 130. Because the p-value of .570 is greater than 0.05 alpha level of significance, the null hypothesis is accepted. Therefore, there is no significant difference in the level of institutional attachment when respondents are grouped according to gender The findings of this problem conform to the study of Mahmoudi (2011) which states that gender had no differential influence over adjustment scores in academic adjustment, emotional and social areas. This implies that Ashong C., \& Commander N., (2012) supports the idea when they say that students tend to be more successful despite of gender and equality.

Table 9. ANOVA in the level of adjustment to college when grouped by academic strand

\begin{tabular}{llccccc}
\hline ADJUSTMENT TOCOLLEGE & $\begin{array}{c}\text { Sum of } \\
\text { Squares }\end{array}$ & df & $\begin{array}{c}\text { Mean } \\
\text { Square }\end{array}$ & F & Sig. \\
\hline Academic & Between Groups & 26.634 & 4 & 6.659 & 5.343 & $.001^{*}$ \\
Adjustment & Within Groups & 158.256 & 127 & 1.246 & & \\
& Total & 184.890 & 131 & & & \\
Social & Between Groups & 8.095 & 4 & 2.024 & 1.581 & .183 \\
Adjustment & Within Groups & 162.537 & 127 & 1.280 & & \\
& Total & 170.632 & 131 & & & \\
Personal- & Between Groups & 1.926 & 4 & .482 & .329 & .858 \\
emotional & Within Groups & 185.857 & 127 & 1.463 & & \\
Adjustment & Total & 187.783 & 131 & & & \\
Institutional & Between Groups & 3.953 & 4 & .988 & .706 & .589 \\
Attachment & Within Groups & 177.860 & 127 & 1.400 & & \\
& Total & 181.814 & 131 & & & \\
Legend: & significant at alpha 0.05 level of significance \\
\hline
\end{tabular}


Table 9 represents the level of adjustment to college when grouped by academic strand. In terms of academic adjustment, the F-value is 5.343. Because the p-value of .001 is lesser than 0.05 alpha level of significance, the null hypothesis is rejected. Therefore, there is significant difference in the level of academic adjustment when respondents are grouped according to academic strand taken during SHS. In terms of social adjustment, the F-value is 1.581 . Because the p-value of .183 is greater than 0.05 alpha level of significance, the null hypothesis is accepted. Therefore, there is no significant difference in the level of social adjustment when respondents grouped according to academic strand taken during SHS. In terms of personal-emotional adjustment, the F-value is .329 . Because the p-value of .858 is greater than 0.05 alpha level of significance, the null hypothesis is accepted. Therefore, there is no significant difference in the level of personal-emotional adjustment when respondents are grouped according to academic strand taken during SHS. Lastly, in terms of institutional attachment, the F-value is .706 . Because the p-value of .589 is greater than 0.05 alpha level of significance, the null hypothesis is accepted. Therefore, there is no significant difference in the level of institutional attachment when respondents are grouped according to academic strand taken during SHS.

The findings of this problem conform to the study of Saileela (2012) that academic strand could not completely affect the level of adjustment when facing the college life. Social, personal-emotional and institutional attachment cannot be affected by what academic strand the student taken during the past school years but it would affect the level of academic adjustment of the student. 
Table 10. ANOVA in the level of adjustment to college when grouped by financial status

\begin{tabular}{llccccc}
\hline ADJUSTMENT TO COLLEGE & Sum of & \multicolumn{5}{c}{ Mean } \\
& & Squares & df & Square & F & Sig. \\
\hline Academic & Between Groups & 5.749 & 6 & .958 & .669 & .675 \\
Adjustment & Within Groups & 179.141 & 125 & 1.433 & & \\
& Total & 184.890 & 131 & & & \\
Social & Between Groups & 14.924 & 6 & 2.487 & 1.997 & .071 \\
Adjustment & Within Groups & 155.708 & 125 & 1.246 & & \\
& Total & 170.632 & 131 & & & \\
Personal- & Between Groups & 12.744 & 6 & 2.124 & 1.517 & .178 \\
emotional & Within Groups & 175.039 & 125 & 1.400 & & \\
Adjustment & Total & 187.783 & 131 & & & \\
Institutional & Between Groups & 9.615 & 6 & 1.603 & 1.163 & .330 \\
Attachment & Within Groups & 172.199 & 125 & 1.378 & & \\
& Total & 181.814 & 131 & & & \\
\hline
\end{tabular}

Table 10 represents the level of adjustment to college when grouped by financial status using ANOVA. In terms of academic adjustment, the F-value is .669. Because the p-value of .675 is greater than 0.05 alpha level of significance, the null hypothesis is accepted. Therefore, there is no significant difference in the level of social adjustment when respondents are grouped according to financial status. In terms of social adjustment, the F-value is 1.997 . Because the p-value of .071 is greater than 0.05 alpha level of significance, the null hypothesis is accepted. Therefore, there is no significant difference in the level of social adjustment when respondents are grouped according to financial status. In terms of personal-emotional adjustment, the F-value is 1.517. Because the p-value of .178 is greater than 0.05 alpha level of significance, the null hypothesis is accepted. Therefore, there is significant difference in the level of personalemotional adjustment when respondents are grouped according to financial status. Lastly, 
in terms of institutional attachment, the F-value is 1.163 . Because the p-value of .330 is greater than 0.05 alpha level of significance, the null hypothesis is accepted. Therefore, there is no significant difference in the level of institutional attachment when respondents are grouped according to financial status.

The findings of the problem conform to the study of Eghbal (2015) that some of the students in college whether they are in middle class in financial students nor in the lower class still able to manage their academic performance in universities and able to cope up the adjustment. Additionally, one out of five students reduced the number of courses they enrolled in due to their finances.

Table 11. ANOVA in the level of adjustment to college when grouped by proximity of house to school

\begin{tabular}{llccccc}
\hline $\begin{array}{l}\text { ADJUSTMENT TO } \\
\text { COLLEGE }\end{array}$ & $\begin{array}{c}\text { Sum of } \\
\text { Squares }\end{array}$ & df & $\begin{array}{c}\text { Mean } \\
\text { Square }\end{array}$ & F & Sig. \\
\hline Academic & Between Groups & .407 & 2 & .204 & .142 & .867 \\
Adjustment & Within Groups & 184.483 & 129 & 1.430 & & \\
& Total & 184.890 & 131 & & & \\
Social & Between Groups & .189 & 2 & .094 & .071 & .931 \\
Adjustment & Within Groups & 170.444 & 129 & 1.321 & & \\
& Total & 170.632 & 131 & & & \\
Personal- & Between Groups & 2.761 & 2 & 1.381 & .963 & .385 \\
emotional & Within Groups & 185.022 & 129 & 1.434 & & \\
Adjustment & Total & 187.783 & 131 & & & \\
Institutional & Between Groups & 10.812 & 2 & 5.406 & 4.078 & $.019 *$ \\
Attachment & Within Groups & 171.002 & 129 & 1.326 & & \\
& Total & 181.814 & 131 & & & \\
\hline Legend: & significant at alpha 0.05 level of significance &
\end{tabular}


Table 11 shows the ANOVA in the level of adjustment to college when grouped by proximity of house to school. In terms of academic adjustment, the F-value is .142. Because the p-value of .867 is greater than 0.05 alpha level of significance, the null hypothesis is accepted. Therefore, there is no significant difference in the level of social adjustment when respondents grouped according to proximity of house to school. In terms of social adjustment, the F-value is 0.71 . Because the p-value of .931 is greater than 0.05 alpha level of significance, the null hypothesis is accepted. Therefore, there is no significant difference in the level of social adjustment when respondents are grouped according to proximity of house to school. In terms of personal-emotional adjustment, the F-value is .963. Because the p-value of .385 is greater than 0.05 alpha level of significance, the null hypothesis is accepted. Therefore, there is no significant difference in the level of personal-emotional adjustment when respondents are grouped according to proximity of house to school. Lastly, in terms of institutional attachment, the F-value is 4.078. Because the p-value of .019 is lesser than 0.05 alpha level of significance, the null hypothesis is rejected. Therefore, there is significant difference in the level of institutional attachment when respondents are grouped according to financial status.

The findings of the problem conform to the study of Andres and Looker (2011)in which it was stated that students raised in a family situated near a university have the obvious cost-saving alternative of staying at home while attending the local university, thus avoiding the added living and moving costs associated with leaving the nest to attend school. Students living "out-of-commuting distance" do not have this option, and may thus be less likely to attend university, especially if they are from a lower income family. 
5. Is there a significant relationship between the level of adjustment to college and academic performance of 1st year radiologic technology students?

Table 12. Pearson r Correlation Among Variables

\begin{tabular}{|c|c|c|c|c|}
\hline & & Academic & & \\
\hline & & & Decision & Interpretation \\
\hline \multirow{4}{*}{ 1. Academic Adjustment } & Pearson & етогты & & \\
\hline & Correlation & -.007 & \multirow{3}{*}{ Accept } & \multirow{3}{*}{ Not Significant } \\
\hline & Sig. (2-tailed) & .939 & & \\
\hline & Pearson & & & \\
\hline \multirow[t]{2}{*}{ 2. Social Adjustment } & Correlation & -.002 & \multirow[b]{2}{*}{ Accept } & \multirow[b]{2}{*}{ Not Significant } \\
\hline & Sig. (2-tailed) & .983 & & \\
\hline $\begin{array}{l}\text { 3. Personal-emotional } \\
\text { adjustment }\end{array}$ & $\begin{array}{l}\text { Pearson } \\
\text { Correlation }\end{array}$ & -.029 & \multirow[b]{2}{*}{ Accept } & \multirow[b]{2}{*}{ Not Significant } \\
\hline \multirow{3}{*}{ 4. Institutional Attachment } & $\begin{array}{l}\text { Sig. (2-tailed) } \\
\text { Pearson }\end{array}$ & .737 & & \\
\hline & Correlation & .047 & \multirow[b]{2}{*}{ Accept } & \multirow[b]{2}{*}{ NotSignificant } \\
\hline & Sig. (2-tailed) & .592 & & \\
\hline
\end{tabular}

Table 12 represents the Pearson $\mathrm{r}$ correlation among variables. Pearson correlation r-value between academic adjustment and academic performance is -.007 and because the p-value of .939 is greater than the 0.05 alpha level of significance, the null hypothesis is accepted. Therefore, there is no significant relationship between academic adjustment and academic performance. Pearson correlation r-value between social adjustment and academic performance is -.002 and because the p-value of .983 is greater than the 0.05 alpha level of significance, the null hypothesis is accepted. Therefore, there is no significant relationship between social adjustment and academic performance. Pearson correlation r-value between personal-emotional adjustment and academic performance is -.029 and because the p-value of .737 is greater than the 0.05 alpha level of significance, the null hypothesis is accepted. Therefore, there is no significant relationship between personal-emotional adjustment and academic performance. Pearson correlation r-value 
between institutional attachment and academic performance is .047 and because the pvalue of .592 is greater than the 0.05 alpha level of significance, the null hypothesis is accepted. Therefore, there is no significant relationship between institutional attachment and academic performance. 


\section{SUMMARY, CONCLUSIONS AND RECOMMENDATIONS}

This section describes the summary, extracts the conclusions, and proposes the recommendations of the study.

\section{Summary}

The thrust of the study was to determine the relationship between adjustment to college and academic performance of $1^{\text {st }}$ year Radiologic Technology students of a higher education institution in the Philippines. Specifically, it sought to know the demographic profile of $1^{\text {st }}$ year Radiologic Technology students of a higher education institution in the Philippines in terms of gender, financial status, academic strand taken during SHS and proximity of house to school; to determine the level of adjustment to college of $1^{\text {st }}$ year Radiologic Technology students of a higher education institution in the Philippines; to know the academic performance of $1^{\text {st }}$ year Radiologic Technology students in terms of Weighted Point Average (WPA), to test the significant difference in the adjustment to college when students are grouped according to gender, income class, academic strand taken during SHS and proximity of house to school; and to test the significant relationship between the level of adjustment to college and academic performance of $1^{\text {st }}$ year Radiologic Technology students. The null hypotheses were formulated and tested at 0.05 level of significance.

A descriptive-correlational study was undertaken at a higher education institution in the Philippines employing first year Radiologic Technology students as respondents. The Slovin's formula was used to calculate the sample size of 131 which was then adjusted to 132 for facility and ease during computation for stratified random sampling technique. The 131 respondents were given questionnaires to gather data on demographic profile and level of 
adjustment to college. After the data were gathered, these were analyzed using the following statistical tools: mean, Pearson R, ANOVA and t-test.

The findings of the study are summarized and arranged as follows:

1. From the sample size of 132, the demographic profile of first year Radiologic technology students in terms of gender is: $61(46.2 \%)$ are males while $71(53.8 \%)$ are females; in terms of financial status is : $16(12.1 \%)$ belong to the poor income class, $14(10.6 \%)$ belong to the low (but not poor) income class, $34(25.8 \%)$ belong to the lower middle income class, $46(34.8 \%)$ belong to the middle income class, $14(10.6 \%)$ belong to the upper middle income class, 5 (3.8\%) belong to the upper income (but not rich) class and $3(2.3 \%)$ belong to the rich income class; in terms of academic strand taken during SHS is: 28 (21.2\%) were from GAS, 12 (9.1\%) were from HUMSS, 78 (59.1\%) were from STEM, 5 (3.8\%) were from $\mathrm{ABM}$ and $9(6.8 \%)$ were from other strands such as ICT; in terms of proximity of house to school is: $43(32.6 \%)$ travel less than one kilometer to school, 45 (34.1\%) travel between one kilometer and 10 kilometers to school and $44(33.3 \%)$ travel more than 10 kilometers to school.

2. The respondents perceived their level of academic adjustment as moderate as indicated by the mean of 3.07 , social adjustment as moderate as indicated by the mean of 3.06, personal-emotional adjustment as moderate as indicated by the mean of 3.01 and institutional attachment as moderate as indicated by the mean of 3.09. The respondents perceived their overall level of adjustment to college as moderate as indicated by the mean of 3.06 . 
3. The academic performance of first year Radiologic Technology students in terms of Weighted Point Average (WPA) during prelim term is 2.63.

4. The test of difference in the level of adjustment to college, specifically the academic adjustment when respondents are grouped according to academic strand during SHS revealed significant difference during ANOVA $(\mathrm{p}<0.05)$. This means that the academic strand taken during SHS affects the level of academic adjustment to college. The test of difference in the institutional attachment when respondents are grouped according to proximity of house to school also reported significant difference during ANOVA $(\mathrm{p}<0.05)$. This means that the proximity of house to school affects the level of institutional attachment. No significant difference was reported among other demographic profiles.

5. The test of relationship using bivariate Pearson $\mathrm{R}$ correlation reported no significant relationship between adjustment to college and academic performance of first $\left(1^{\text {st }}\right)$ year radiologic technology students.

\section{Conclusions}

Based on the findings of the study, the following conclusions are drawn:

1. The majority of the first $\left(1^{\text {st }}\right)$ year radiologic technology student-respondents are female, belong to middle income class, were from STEM strand and travel between one kilometer and 10 kilometers to school.

2. Student-respondents adjust to college often in terms of academic, social personalemotional and institutional attachment. Respondents adjust to college often in terms of overall level of adjustment to college. 
3. There is significant difference in the level of academic adjustment to college when respondents are grouped according to academic strand taken during SHS. There is also significant difference in the level of institutional attachment when respondents are grouped according to proximity of house to school. There is no significant difference in the level of social and personal-emotional adjustments to college when respondents are grouped according to demographic profile.

4. There is no significant relationship between adjustment to college and academic performance of first year Radiologic Technology students.

\section{Recommendations}

Based on the findings of the study and conclusions, the following recommendations are given:

1. The high school students should choose the right academic strand that is fit to their undergraduate degree to be taken during college since academic strand can significantly affect the academic adjustment of students.

2. The first year Radiologic Technology students should involve in activities that can strengthen their adjustment to college. These include attending all the discussions or lectures, reading and exploring new books and reviewing notes regularly.

3. The school administrator and faculty should implement programs that can intensify adjustment of students to college.

4. The future researchers may include other variables that can affect the level of adjustment to college and academic performance of first year Radiologic Technology students. 


\section{REFERENCES}

Abdullah, M.C., Elias, H., Mahyuddin, R. \& Uli, J. (2009). Adjustment among first year students in a Malaysian university. European Journal of Social Sciences, $\quad 8(3), \quad$ 496-505. Retrieved from: http://www.europeanjournalofsocialsciences.com/ejss_issues.html

Alipio, M. M. (2020). Academic Adjustment and Performance among Filipino Freshmen College Students in the Health Sciences: Does Senior High School Strand Matter?.

Alipio, M. M. (2020). Predicting Academic Performance of College Freshmen in the Philippines using Psychological Variables and Expectancy-Value Beliefs to Outcomes-Based Education: A Path Analysis.

Alipio, M. M., Felizarte, L. P., \& Revilla, D. L. Outcomes-Based Education Approach Correlates and Academic Performance of College Radiologic Technology Freshmen. Retrieved from https://www.academia.edu/42265142/OutcomesBased_Education_Approach_Correlates_and_Academic_Performance_of_College _Radiologic_Technology_Freshmen

Astin, A.W. (1982). Minorities in American higher education. San Franci sco, Josse y- Bass

Ashong C. \& Commander N., (2012) MERLOT Journal of Online Learning and Teaching Vol. 8, No. 2, June 2012

Baker, R., \& Siryk, B. (1989). The Student Adaptation to College Questionnaire (SACQ). Western Psychological Services.

Burgess T, Crocombe L, Kelly J, Seet P. S.,(2009). The effect of cultural background on the academic adjustment of first year dental students. Ergo, 1(2): 5-24.

Calaguas, G. (2011). Academic achievement and academic adjustment difficulties among college freshmen. International Refereed Research Journal, 2(3).

Chen. X., Rubin, Kenneth H. Li, Dan, (2011). Relation betweenAcademic Achievement and SocialAdjustment: Evidencefrom Chinese Children. Journal of Developmental Psychology. Canada : May Vol.33(3), 518-525.

Clinciu, A. I. (2012). Adaptation and Stress for the First Year University Students Procedia-Social and Behavioral Sciences, 78, 718-722. doi:https://doi.org/10.1016/j.sbspro.2013.04.382

Clinciu, A. I., \& Cazan A. M., (2013). Academic Adjustment Questionnaire for the university students. Procedia-Social and Behavioral Sciences, 127,655-660.

Daniel, C., Ajayi, A., Ogunyewo, O., Ajio, D., Andy, E., Oyedele, E., Gusen, N. (2018). Perceived impact of academic stress on academic performance among undergraduate nursing students of university of Jos. New Nigerian Journal of Clinical Research, 7(11), 8-15. doi:10.4103/nnjcr.nnjcr_38_16 
Eghbal C. (2015) Comparison of the Efficiency of Self-awareness, Stress Management, Effective Communication Life Skill Trainings on the Social and Academic Adjustment of First-year Students. Research in Psychology and Behavioral Sciences. 2015; 3(2):18-24. doi: 10.12691/rpbs-3-2-1.

Elias, H., Ping, W. S., \& Abdullah, M. C. (2011). Stress and Academic Achievement among Undergraduate Students in Universiti Putra Malaysia. Procedia - Social and Behavioral Sciences, 29, 646-655. doi:https://doi.org/10.1016/j.sbspro.2011.11.288

Fan, W., \& Wolters, C. A. (2014). School motivation and high school dropout: The mediating role of educational expectation. British Journal of Educational Psychology, 84(1), 22-39. doi:doi:10.1111/bjep.12002

Gabriela, C. (2010). A case study into the causes of school dropout (Vol. 3). BabesBolyai University: Acta Didactica Napocensia.

Habibah E, Noordin N, Mahyuddin RH 2010. Achievement motivation and self- efficay in relation to adjustment among university students. Journal of Social Sciences, 6(3): 333-339.

Hernandez, R. (2017) Asia Pacific Journal of Multidisciplinary Research Vol. 5 No.3, 4956 August 2017

Keating, X., Guan, J., Pinero, J., \& Bridges, D., (2010). A MetaAnalysis of College Students' Physical Activity Behaviors. Journal of American College Health, 54(2), 116-125.

Kommers P., Junco R., Hills P., (2011) Social Media for Learning by Means of ICT, pl10, UNESCO Institute for Information Technologies in Education, UNESCO Moscow

Kumar A., (2010). Study of Academic Achievement, Values and adjustment of Secondary Schol Students in Relation to Working Status of Mothers, College of Education, Pathankot

Lapsley, D. K., \& Edgerton, J. (2002). Separation-individuation, adult attachment style and college adjustment. Journal of Counseling \& Development, 80(4),484-492.

Lapsley, D. K., Rice, K. G., \& FitzGerald, D. P. (2009). Adolescent attachment, identity, and adjustment to college: Implications for the continuity of adaptation hypothesis. Journal of Counseling \& Development, 68(5), 561-565.

Mahmoudi S. (2011) Social life adjustment and academic achievement of adolescents in EDO state: Implication for counseling. Ozean Journal of applied Sciences 5(2), 2011

Mathur. K. 2010. Effects of Socio-Economic Status on the Achievement and Behaviour of Higher Secondary School Students. Unpublished Ph.D. Thesis. Agra Univ. 
McDermott, L. A., \& Pettijohn, T. F. (2011). The influence of clothing fashion and race on the perceived socioeconomic status and person perception of college students. Poster presented at the 23rd Annual Association for Psychological Science Convention, Washington, D.C.

Meeuwisse, M., Severiens, S. E., \& Born, M. P. (2010). Reasons for withdrawal from higher vocational education. A comparison of ethnic minority and majority noncompleters. Studies in Higher Education, 35(1), 93-111.

Mitchell, M. L., \& Jolley, J. M. (2012). Research Design Explained: Cengage Learning.

Mohamed, N. (2012). Adjustment to University: Predictors, Outcomes and Trajectories (Unpublisded doctoral dissertation). University of Central Lancashire.

Monroe, P. (2009). International encyclopaedia of education. (Ed.) New Delhi: Cosmo Publications

Najimi A, Moazemi Goudarzi A, Sharifirad G. (2012). Causes of job stress in nurses: A cross-sectional study.Iran J Nurs Midwifery Res. 2012;17(4):301-05

Organisation for Economic Co-operation and Development, AHELO Feasibility Study Report - Volume 1, 2011

Páramo, F., Vacas, C., \& Rodriguez, S. (2015). Levels of adjustment to college, gender and academic achievement in first-year Spanish students.

Peter James K., Inter Andy J., Tracy O., (2014) Academic Achievement Prediction: Role of Interest in Learning and Attitude towards School, National Journal of Humanities Social Sciences and Education (IJHSSE) Volume 1, Issue 11, November 2014, PP 73-100.

Petersen, I. h., Louw, J., \& Dumont, K. (2009). Adjustment to university and academic performance among disadvantaged students in South Africa. Educational Psychology, 29(1), 99-115. doi:10.1080/01443410802521066

Rai, P. N. (2009). A Comparative Study of a Few Differential Personality Correlates of Low and High Achievers. Unpublished Ph.D. Thesis, Agra Univ.

Reddy, K. J., Menon, K. R., \& Thattil, A. (2018). Academic Stress and its Sources Among University Students. Biomed Pharmacol J, 11(1).

Rice, K. G. (2009). Separation-individuation and adjustment to college, A longitudinal study. Journal of Counseling Psychology, 39, 203-213. http://dx.doi.org/10.1037/0022-0167.39.2.203

Rienties, B., Beausaert, S., Grohnert, T., Niemantsverdriet, S., \& Kommers, P. (2011). Understanding academic performance of international students: 90 The role of ethnicity, academic and social integration. Higher Education Quarterly, 63, 685700 . 
Robinson, J. (2009). "International students and American university culture: Adjustment Issues", Paper presented at the meeting of the Washington Area Teachers of English to Speakers of Other Languages Annual Convention, Arlington, VA.

Russell, J., Rosenthal, D., \& Thomson, G. (2010). The international student experience: three styles of adaptation. Higher Education, 60(2), 235-249. doi:10.1007/s10734009-9297-7

Sahin, S., Arseven, Z., \& Kilic, A. (2016). Causes of Student Absenteeism and School Dropouts (Vol. 9).

Seetha, B.C. (2009). An Inquiry into the Psychological and Social Factors Affecting Academic Achievement. Unpublished Ph.D. Thesis. Ban. Univ.

Tinto, V. (2002). Enhancing student persistence: Connecting the dots. Retrieved June 5, 2006 from http://www.wiscape.wsc.edu/publications/attachments/419Tinto.pdf

UNICEF (2011). UNICEF Says 6.6 million Zimbabweans Living Below Food Poverty Line. Retrieved fromhttp://www.voanews.com/Zimbabwe/news

Waghachavare, V. B., Dhumale, G. B., Kadam, Y. R., \& Gore, A. D. (2013). A Study of Stress among Students of Professional Colleges from an Urban area in India. Sultan Qaboos Univ Med J, 13(3).

Wilson D., (2013). The interface of school climate and school connectedness and relationships with aggression and victimization. Journal of School Health. 2013;74:293-299 